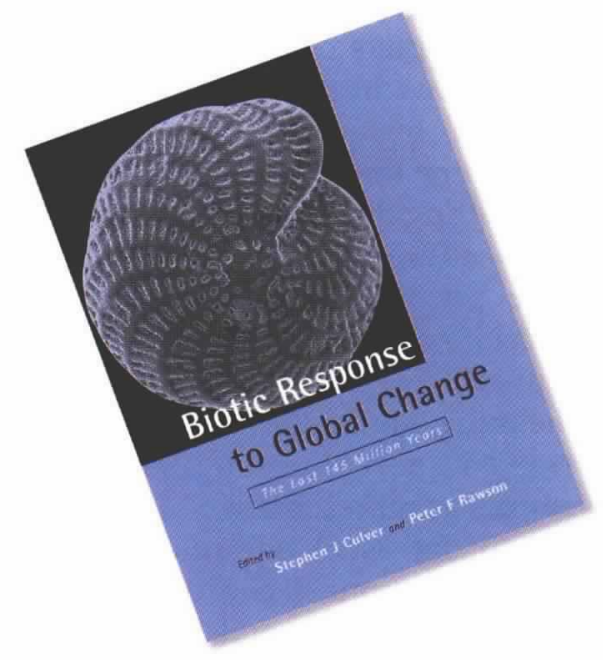

\section{Biotic Response to Global Change: The Last 145 Million Years}

\author{
Edited by Stephen J. Culver and Peter F. Rawson \\ Cambridge University Press \\ ISBN 0-521-66304-0, 501 pages \\ Review by \\ Patrick M. Holligan \\ School of Ocean and Earth Science, Southampton \\ Oceanography Centre, UK
}

This volume has its origins in a joint research program between the Natural History Museum, London and University College, London on Global Change and the Biosphere. The authors are mainly paleontologists, and include contributors to the program as well as invited specialists. They were all given the charge of documenting patterns in fossil data in relation to their knowledge and understanding of environmental change at scales ranging from global to regional/local. The result is a fascinating mixture of observations and interpretation about the remarkable changes that have occurred in both the environment and biota of the Earth over the last 145 million years (my).

This period of time, representing just 3\% of Earth's history, covers the transition from Cretaceous 'greenhouse' conditions to later Cenozoic 'icehouse' conditions, includes major species extinction events (in particular the $\mathrm{K} / \mathrm{T}$ boundary 65 my ago), and saw the rapid evolution of both flowering plants and mammals as significant global constituents of the biota. Furthermore, the first development of major polar ice sheets about 14 my ago (probably linked to earlier major changes in the positions of continents and in ocean circulation), the origin of ancestors of Homo sapiens about 5 my ago, and the onset of the Quaternary period of marked and rapid climate fluctuations about 2 my ago provide a dramatic background to our modern concerns about global change. Rapid changes in our environment are thus seen as the norm. For example, reconstructing the response of the biota to an increase in regional temperature by as much as $9^{\circ} \mathrm{C}$ within about 50 years during the Holocene deglaciation, at the termination of the Younger Dryas about 10 thousand years ago, places an interesting perspective on our immediate concerns about the biological impacts of a predicted global anthropogenic warming of 1.4 to $5.8^{\circ} \mathrm{C}$ in the $21^{\text {st }}$ century.

Each main chapter considers, for a particular group of organisms, the nature and causes of biotic change. The causes include abiotic factors, for the main part climate-related, and biotic ones which may be either intrinsic (e.g. evolution of new genotypes) or extrinsic (interactions between species and communities of organisms). The organisms range from various marine protist and invertebrate groups, to terrestrial plants, insects and vertebrates, and finally humans. Two introductory chapters provide concise and helpful descriptions of global environmental conditions during the Cretaceous and Cenozoic periods, and a final summary chapter draws together the various conclusions about how the biota has responded to past environmental change. The format and level of detail of each chapter are quite varied, largely reflecting the nature of the different fossil records and the scales over which they have been analyzed, but demand little prior knowledge; this feature of the book may frustrate some specialist paleontologists, but serves to make the general reader aware both of how little we still know about the past and of the dangers of drawing hard conclusions from particular sets of information.

The book raises many interesting questions, which future scientists will spend much time trying to answer. For example, "Do nanoplankton exert a real feedback on the climate system?"; "How did coral reefs as we know them today first develop?"; "How many species really disappeared at extinction events?"; "What are the implications for global biodiversity of the strong latitudinal gradients in climatic conditions that characterize the Quaternary period?"; "What is the relative importance of the rates of evolution of new genotypes and of species migration in response to climate change for the development of terrestrial plant communities?"; and "Has global environmental change had a significant influence on the evolution and domination of modern humans?" However, important as such questions are, 
they all now have to be examined within the context of the large-scale human influences on the global environment. So far the need to do this in terms of the potential anthropogenic effects on the climate system has been recognized internationally but the implications for the future of the global environment of direct impacts of humans on ecosystems, both terrestrial and marine, remains a much more difficult topic for research. This situation reflects complex socio-economic and political sensitivities with which natural scientists are generally not well equipped to deal.

This book rightly does not attempt to address this last issue. However, it seems a pity that no synthesis was included of modern understanding of the dynamics of the Earth and its environment as a system that has allowed life to evolve and sustain itself over geological time. Earth system science has much to learn from paleontology and, if paleontologists wish to promote the concept that 'knowledge of the past is the key to the future', then a much greater knowledge will be needed about how global biogeochemical cycles operated in the past and how they were affected by events such as major volcanic activity, bolide impacts and changes in ocean circulation. This comment aside, the book makes very enjoyable reading especially for the non-geologist who will learn much about the recent history of our globe that is highly relevant to evaluating the potential impacts of anthropogenic global change.

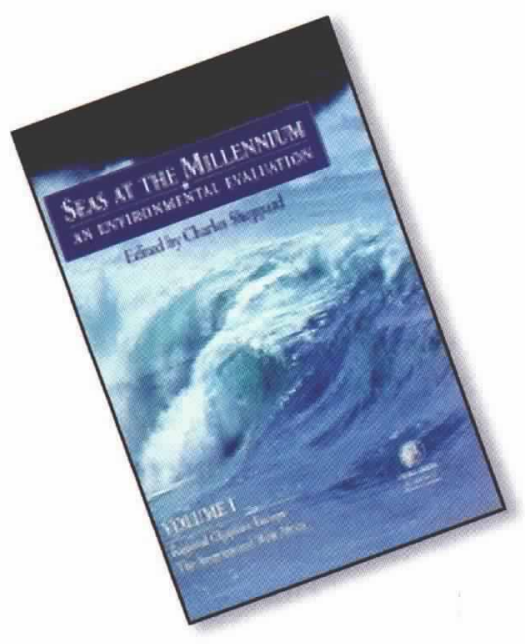

Seas at the Millennium: An Environmental Evaluation

Edited by Charles Sheppard

Pergamon Press of Elsevier Science

ISBN 0-08-043207-7, 3 Vols., Approx. 2400 pages

Review by David A. Brooks

Texas AEM University, College Station, Texas USA
This massive collection of interdisciplinary review articles about the coastal oceans is offered as a reference source for "researchers and policy makers with an interest in the marine environmental sciences, oceanography and marine engineering." In sheer bulk the work is unsurpassed, the three volumes comprising 2352 pages and weighing in at $44 \mathrm{~kg}$. The first two volumes contain 106 review chapters covering selected coastal, shelf and marginal seas in the Atlantic, Indian and Pacific Oceans. Polar regions are not considered, a major omission. Volume three adds 29 review chapters on diverse cross-cutting themes such as coral reefs, seabirds, marine antifoulants, and tidal energy. According to the publisher's promotional material, individual chapters are authored by "international experts and scientists working in the field."

The overwhelming (and audacious) scope of such a collection defies even a partial reading, so I have taken a few "core" samples as representative of the whole, an approach subject to the usual hazards of undersampling. From the first volume I chose three chapters describing areas familiar to me and from the second volume three chapters covering less-familiar regions, supposing that satisfaction with the former would lend credence to the latter. From the last volume I selected three chapters on topics of general interest. Readers should note that this set comprises only about $6 \%$ of the total number of chapters and judge accordingly. Also in the spirit of full disclosure it should be noted that the reviewer's primary bias is physical oceanography.

All the selected articles provide a broad interdisciplinary introduction to the biogeochemical aspects of the region reviewed, with a wide focus on sustainability issues. Topics include physical, biological and chemical descriptions of the ocean, estuarine and bay ecosystems; the nearshore coastal zone and its built infrastructure; the influence of burgeoning coastal populations and resulting pollution and impacts on habitats; status and trends of fisheries; and species diversity. The sweeping scope is appropriate for a reference work intended to give thumbnail overviews of the environment, but the predictable result even in such a massive undertaking is a rather thin and uneven spread.

I found the chapters dealing with familiar regions to be severely dated. In some cases important work from the last few decades has been completely overlooked or omitted. Lack of currency can be expected in large, multi-author volumes, but the staleness here seems excessive. I was struck by the preponderance of technical reports and other "gray" literature in bibliographic citations, and by the lack of references to wellknown authors who have long been actively working in the regions reviewed. Consequently these chapters provide a general overview useful in the same way that an encyclopedia might introduce a casual reader to a topic. For students and others with a more serious interest in the state of the science, there are better and much more current sources of information available, as a topical search on the Internet quickly will reveal. 